\title{
OPROGRAMA DE PÓS-GRADUAÇÃO EM EDUCAÇÃO DA UNESP DE MARÍLIA: CONTRIBUIÇÕES PARA UMA AGENDA DE DISCUSSÕES SOBRE ASPECTOS DA POLÍTICA DE PÓS-GRADUAÇÃO NO BRASIL
}

\author{
Rosane Michelli de CAStro*
}

Recebido: jul. 2010

Aprovado: out. 2010

*Dra. em Educação, Pós-Doutorado pela Fundação Carlos Chagas (2010). Professora assistente na Faculdade de Filosofia e Ciências - FFC-UNESP/Marília. E-mail: rosanemichelli@marilia.unesp.br

Resumo: Apresentam-se parte dos resultados obtidos com as atividades de pesquisa desenvolvidas em nível de estágio pós-doutoral junto à Fundação Carlos Chagas, entre abril de 2009 e março de 2010, com o objetivo geral de identificar, reunir, analisar e interpretar os aspectos da Pós-Graduação em Educação da Faculdade de Filosofia e Ciências - FFC - Unesp/Campus de Marília (1988-2008) e suas contribuições para a Pós-Graduação no Brasil. Tal pesquisa se justifica considerando-se que, a avaliação dos aspectos da trajetória pregressa e da evolução de cada Programa de Pós-Graduação e seu contexto institucional, bem como as suas perspectivas de trajetória futura, concorrem para a história, para a redefinição e aperfeiçoamento dos aspectos da política de Pós-Graduação no Brasil. Particularmente neste texto, apresentamos os resultados dos trabalhos desenvolvidos mediante análise dos aspectos da configuração textual dos relatos orais de ex-partícipes do Programa que evidenciaram desafios que, historicamente, permanecem em aberto, dentre eles, os referentes ao desequilíbrio quanto à representatividade dos Programas das universidades estaduais com relação aos das estaduais nos órgãos colegiados centrais e à exigência de super especialização dos Programas quanto às suas propostas de investigação.

Palavras-chave: Educação. Pós-Graduação. Pós-Graduação em Educação da UNESP de Marília. Política de Pós-Graduação no Brasil.

THE GRADUATE PROGRAM IN EDUCATION AT UNESP IN MARÍLIA: CONTRIBUTIONS TO A DISCUSSION ON ASPECTS OF THE POLICIES FOR GRADUATE PROGRAMS IN BRAZIL

Abstract: In this article we present part of the results obtained from the research activities developed during a post-doctorate internship at the Carlos Chagas Foundation, between April of 2009 and March of 2010. The general purpose of the research was to identify, gather, analyze and interpret the aspects of the graduate program in education at the Marilia Campus of UNESP's Science and Philosophy School (1988 - 2008) and their contributions to graduate level education in Brazil. This research is justified when one considers that the evaluation of aspects of the previous trajectory and of the evolution of each graduate program and its institutional context, as well as of its future perspectives contribute to the history, the redefinition and the improvement of the policies regarding graduate level education in Brazil. Particularly in this text, we present the results of works developed by analysis of the textual configuration aspects from oral reports of former participants in the Program. They highlighted the challenges that historically remain open. Among them, those concerning to the unbalance of representativeness of state university programs in relation to the federal university programs in central collegiate organizations and relating to the requirement of over specialization in the Programs in relation to their investigation proposals.

Key words: Education. Graduate programs. Aspects of the graduate program in Education at Marilia UNESP. Graduate level education policies in Brazil. 


\section{INTRODUÇÃO}

Neste artigo, apresentamos parte dos resultados obtidos com o desenvolvimento das atividades de pesquisa desenvolvidas com o objetivo geral de identificar, reunir, analisar e interpretar os aspectos da Pós-Graduação em Educação da Faculdade de Filosofia e Ciências - FFC - Unesp/Campus de Marília (1988-2008) e suas contribuições para a Pós-Graduação no Brasil.

A proposição desta pesquisa para ser desenvolvida em nível de estágio pós-doutoral junto à Fundação Carlos Chagas, entre abril de 2009 e março de 2010, particularmente na linha de pesquisa "Avaliação Educacional" se deve à crença de que as universidades e os centros universitários e, particularmente, os sujeitos vinculados aos seus cursos e programas de pós-graduação em educação stricto sensu - mestrados e doutorados, partilham de motivações que lhes são, em certa medida, peculiares, mas que, no seu conjunto, formam um todo, cujas perspectivas de desenvolvimento dependem da retomada e da avaliação dessas peculiaridades frente às exigências contextuais.

Segundo Cordova, Gusso e Luna (1986), a própria criação dos cursos e programas de pós-graduação é fruto de razões internas compartilhadas entre os sujeitos. Formam o que se podemos chamar de certa dinâmica própria de seus pesquisadores; partilham de um tempo e espaço históricos que têm características de vida próprias, seus ritmos, ritos, linguagem, imaginário, referenciais teóricos e metodológicos, modos próprios de regulação e de transgressão, seu regime e meios próprios de produção e diálogo com seus pares.

Acreditamos que essa dinâmica sui generis é capaz de extrapolar os limites da instituição e imprimir a sua marca acadêmica a toda espécie de atividade a ela relacionada, evidenciada em suas práticas e concepções, sobretudo nos processos de disseminação do conhecimento produzido por meio dos vários meios, situações e espaços.

Daí ser possível admitirmos que, a exemplo dos demais programas de pósgraduação em educação stricto sensu de relevante contribuição para a área, também o da Unesp de Marília possui sua dinâmica que congrega os seus pesquisadores, suas produções e seus modos e fazeres docentes, cujas contribuições carecem de ser evidenciadas e avaliadas para se enfrentar os desafios postos à pós-graduação na atualidade.

Nesse sentido, buscamos proceder em direção a uma avaliação mais de caráter descritivo e cumulativo de aspectos da trajetória do Programa em questão, a fim de se chegar, possivelmente, a uma síntese dessa trajetória que apre- 
sentasse maior proximidade com as possíveis respostas aos questionamentos orientadores da investigação proposta, a saber:

- O que representou a criação do Programa de Pós-Graduação em Educação stricto sensu, mestrado e doutorado, na Unesp de Marília, para a área da educação e para a pós-graduação em educação no Brasil, para a região do estado em que ele foi criado e para a própria Unesp?

- Quais os principais objetivos perseguidos, ao longo dos anos, pela Pós-Graduação em Educação da Unesp de Marília e qual a base teórica orientadora das suas atividades quanto à natureza das atividades acadêmico-científicas que haveriam de desenvolver? Nesse sentido, foi possível o Programa em questão vivenciar uma experiência acadêmico-científica em que é possível identificar contribuições para a área da educação e para a pesquisa educacional no Brasil? Quais as principais dificuldades encontradas nessa trajetória?

- A Pós-Graduação em Educação da Unesp de Marília manteve e/ou fomentou os seus aspectos que lhes possibilitou a criação e desenvolvimento durante seus 20 anos primeiros anos? Tais aspectos lhe conferiram e/ou conferem alguma originalidade?

- Como o Programa de Pós-Graduação em Educação da Unesp de Marília tem respondido, ao longo dos anos, às exigências dos órgãos oficiais e agências de fomento a ele impostas?

- Quais as perspectivas de desenvolvimento futuro do Programa?

- Quais as tendências temáticas predominante nas pesquisas desenvolvidas no Programa da Pós-Graduação em Educação da Unesp de Marília? Foram privilegiadas as investigações sobre a formação dos professores?

- A formação de professores para o ensino superior foi privilegiada na Pós-Graduação em Educação da Unesp de Marília?

Para a recuperação dos dados e informações que serviram de base para o desenvolvimento dessa investigação, foram utilizadas fontes primárias cuja organização e sistematização foi feita mediante a elaboração dos seguintes instrumentos de pesquisa:

- Relatos orais dos sujeitos que estiveram à frente das primeiras idéias e do primeiro projeto de Pós-Graduação em Educação da Unesp de Marília, alguns dos quais também estiveram à frente das primeiras ativida- 
des de administração e de docência no Curso de Mestrado em educação stricto sensu então criado, coletados por meio das entrevistas semi-estruturadas ${ }^{1}$;

- Referências das teses e dissertações desenvolvidas no Programa de Pós-Graduação em Educação da Unesp de Marília entre 1988 e 2008, em busca, dentre outros aspectos, da identificação das suas temáticas e de informações sobre a quantidade e o perfil dos mestres e doutores em educação formados por esse Programa.

- Relatórios anuais e trienais sobre o Programa de Pós-Graduação em Educação da Unesp de Marília apresentados em cumprimento às exigências da CAPES, em busca de informações, a partir das quais buscamos identificar as metas perseguidas, os principais desafios e principais projetos e perspectivas para o enfrentamento a esses desafios.

Ainda, além dessas fontes, buscamos nos valer de um conjunto de documentos, fontes primárias recuperadas junto ao pessoal da administração atual do Programa de Pós-Graduação em Educação da Unesp de Marília.

As etapas de análise e interpretação dos dados e informações reunidas foram desenvolvidas segundo o método de "análise dos elementos da configuração textual” como concebido por Magnani (1993, 1997) e Mortatti (2000). São elementos da configuração textual:

[...] conjunto de aspectos constitutivos de determinado texto, os quais permitem à investigadora reconhecê-lo e interrogá-lo como objeto singular e vigoroso (STAROBINSKI, 1988) e dele produzir uma leitura possível e autorizada, a partir de seus objetivos, necessidades e interesses. Tais aspectos referem-se: às opções temáticoconteudísticas (o quê?) e estruturais-formais (como?), projetadas por um determinado sujeito (quem?), que se apresenta como autor de um discurso produzido de determinado ponto de vista e lugar social (de onde?) e momento histórico (quando?), movido por certas necessidades (por quê?) e propósitos (para quê), visando a determinado efeito em determinado tipo de leitor (para quem?) e logrando determinado tipo de circulação, utilização e repercussão. (MAGNANI, 1997, p. 31).

1 Com exceção do Prof. Wilson de Faria, presidente da primeira comissão para a elaboração do Projeto inicial, em virtude de ser ele falecido, foi possível entrevistarmos todos os demais partícipes, os quais faremos menção pelas iniciais dos seus nomes: Prof . ${ }^{\mathrm{a}}$ J. C. P., que teve as primeiras idéias de elaboração do projeto; Professores: C. A. S. Jr., S. O. e J. M. F. V. que fizeram parte da primeira comissão para elaboração do projeto; e, Prof. ${ }^{a}$ M. L. M. H., professora que acompanhou os trabalhos desde o início e, posteriormente, professora do Programa de Pós-Graduação em Educação da Unesp de Marília, como se mantém até os dias atuais. 
Neste texto, apresentaremos parte dos resultados obtidos com os trabalhos de análise dos relatos orais coletados por meio de entrevista semi-estruturada feita com o Prof. C. A. S. Jr., professor que esteve à frente das primeiras idéias e do primeiro projeto para a criação de um Programa de Pós-Graduação em Educação na Unesp de Marília, das primeiras atividades de administração e que, por duas gestões, foi coordenador desse programa, tendo, ainda, se dedicado às atividades de docência e de orientação no Programa em questão.

Procedemos a esse recorte considerando-se que os resultados obtidos com os trabalhos mencionados evidenciaram aspectos da trajetória do Programa de Pós-Graduação em Educação da UNESP de Marília, cuja retomada e reflexão nos conduziram a questões que ainda carecem de discussões e que dizem respeito à política de Pós-Graduação no Brasil, como as referentes ao desequilíbrio quanto à representatividade dos programas de pós-graduação das universidades estaduais e das universidades federais nos órgãos colegiados nacionais, e à exigência da super especialização das propostas de investigação dos programas.

\section{O PÓS-GRADUAÇÃO EM EDUCAÇÃO DA UNESP DE MARÍLIA: ASPECTOS HISTÓRICOS}

Em 09/09/1985, foi enviado para o então diretor da Faculdade de Educação, Filosofia, Ciências Sociais e da Documentação - FEFCSD - Unesp/Campus de Marília, ${ }^{2}$ Prof. Dr. Alvanir de Figueiredo, para a tramitação competente, o primeiro projeto destinado à instalação do Curso de Pós-Graduação em Educação, em nível de mestrado, com duas Áreas de Concentração: "Ensino na Educação Brasileira" e "Administração da Educação Brasileira".

Esse projeto foi enviado pelo presidente da comissão constituída para a sua elaboração, Prof. Dr. Wilson de Faria. Integraram, ainda, a referida comissão, designada pela Portaria n. 73/84, outros professores dos vários departamentos da FEFCSD, a saber: Dr. Celestino Alves da Silva Jr., Dr. José Misael Ferreira do Vale, Dr. Sadao Omote e Dr. Vilmo Guimarães Melo.

Com o objetivo de o curso ser o único em educação da Unesp e iniciar as suas atividades já em março de 1986, deveria envolver as seguintes Unidades Universitárias e Departamentos:

- Campus de Marília - FEFCSD: Dep. de Administração e Super-

2 Em 1989, essa Faculdade passou a denominar-se Faculdade de Filosofia e Ciências - FFC - Unesp/ Marília. 
visão Escolar, Dep. de Didática, Dep. de Psicologia da Educação, Dep. de Educação Especial, Dep. de Sociologia e Antropologia, Dep. de Filosofia, e Dep. de Ciências Políticas e Econômicas.

- Campus de São José do Rio Preto - IBLCE: Dep. de Educação.

- Campus de Assis - ILHP: Dep. de Psicologia.

- Campus de Botucatu - IBBMA: Dep. de Educação.

Além dessas Unidades Universitárias, os campi de Presidente Prudente IPEA e o de Araraquara - ILCSE deveriam fornecer professores para o corpo de orientadores.

As justificativas para a elaboração desse projeto para a implantação de um curso de pós-graduação em educação, primeiramente em nível de mestrado, no Campus de Marília eram, segundo o texto do projeto (FEFCSD, 1985, p. 11) de duas ordens: "[...] de caráter prático-institucional, ou seja, a existência de condições de ordem pessoal, material e de tradição acadêmica que [estariam a oferecer] sustentação ao projeto elaborado [...] e de ordem teóricoconceitual em que ele [se apoiava][...]"

Em relação ao primeiro critério era destacada a história dos estudos em educação no Campus de Marília, considerada pelos professores como significativa e relevante para a educação na região. Em especial, ressaltavam a trajetória do seu Curso de Pedagogia e dos seus professores que afirmavam:

[...] acumular considerável experiência de ensino e pesquisa que se [expressava] não só nos cursos regulares de graduação desenvolvidos, mas também e, principalmente, nas diferentes experiências de extensão e de especialização que [vinham] se realizando ao longo dos anos (UNESP.FEFCSD, 1985, p. 11).

Alegavam que o Campus de Marília e, particularmente, o Curso de Pedagogia ofereciam sete habilitações (incluindo a de Educação Especial) para uma formação consistente dos professores da região, para o que contavam com significativa quantidade de docentes que se distribuíam por variadas áreas de especialização profissional.

Quanto às condições materiais do Campus de Marília, afirmavam que eram satisfatórias as instalações, os equipamentos e os locais de trabalho docente e de pesquisa.

Quanto à localização geográfica do Campus de Marília, afirmavam tratarse de um outro importante elemento de ordem material a ser considerado: 
Sua notória influência na região centro-oeste paulista fazem do campus de Marília um pólo privilegiado de atendimento às necessidades regionais, tal como se preconiza na própria política de descentralização proposta pelo Governo do Estado. Deve-se registrar ainda a existência na cidade de Marília de sua Faculdade de Medicina, mantida por uma Fundação ligada à Prefeitura Municipal e de onde emerge um significativo potencial de atividades em cooperação destinadas ao aprofundamento de investigações na importante área comum de trabalho entre educação e saúde. Esta cooperação já se faz notar atualmente na área de graduação em educação especial. (UNESP.FEFCSD, 1985, p. 12).

Segundo Santos (2000, p. 46), considerando que os cursos de pós-graduação existentes, à época, no estado de São Paulo, situavam-se na capital (USP e PUC), em Campinas (Unicamp) e em São Carlos (UFSCar), uma pós-graduação em educação em Marília seria de grande importância para o centro-oeste e norte do estado de São Paulo, além das regiões do norte do Paraná e das regiões mais próximas do Mato Grosso (atual Mato Grosso do Sul) e de Goiás.

Em relação ao projeto do Curso de Pós-Graduação em Educação, as afirmações eram as de que "[...] ao mesmo tempo em que [atendia] à tríplice função universitária de ensino, pesquisa e serviço à comunidade, constituía desafio à capacidade acadêmica de responder, produtivamente, a cada uma dessas finalidades." (UNESP.FEFCSD, 1985, p. 12). Nesse sentido, entendiam que deveriam centrar a proposta básica de trabalho do Curso no tema "Educação Brasileira", de onde pretendiam derivar outros temas e as metodologias de pesquisa necessárias à ampliação e ao desenvolvimento desse importante campo de estudos especializados, e no interior do qual duas áreas de concentração deveriam se constituir: "Ensino na Educação Brasileira" e "Administração da Educação Brasileira".

Nessa mesma perspectiva, temas e questões a serem trabalhados em cada área de concentração e em cada disciplina foram explicitados, bem como aspectos da metodologia a ser adotada e das diretrizes básicas orientadoras do planejamento do programa de cada disciplina do Curso, válidas para as duas áreas de concentração.

Em 15 de janeiro de 1986, o referido projeto foi encaminhado ao Prof. Dr. Antonio Manoel dos Santos Silva, então Presidente da Câmara Central de Pós-Graduação e Pesquisa da UNESP, quem designou um parecerista no âmbito da própria Unesp, do Campus de Assis, Prof. Dr. José Ribeiro Júnior, 
representante discente junto à Câmara Central de Pós-Graduação e Pesquisa CCPG - da Unesp, quem, em 03 de fevereiro de 1986, se manifestou mediante parecer favorável "[...] à criação do Curso de Pós-Graduação em Educação solicitado pelo Campus de Marília." (p. 995).

Em fevereiro de 1986, recebido o parecer favorável, a CCPG solicitou o envio de todo o processo a especialista do Curso de Pós-Graduação da Unicamp, Professor Doutor Moacyr Gadotti que, mesmo tendo apontado questões a serem retomadas, se manifestou favorável ao projeto.

Aprovado pela CCPG e pelo Conselho de Ensino, Pesquisa e Extensão Universitária - CEPE, o processo foi encaminhado, em 27/08/1897, ao Conselho Universitário - CO da Unesp - para análise e parecer do Conselheiro Prof. Dr. Antonio Christofoletti, do Instituto de Geociências e Ciências Exatas de Rio Claro (IGCERC) da Unesp. Esse Conselheiro solicitou, diante das sugestões dos demais pareceristas, as devidas providências para que, finalmente, o Curso de Mestrado em educação pudesse iniciar as suas atividades em 1988.

Assim, os integrantes da Comissão de Pós-Graduação da FEFCSD Unesp/Campus de Marília elaboraram um novo documento em que buscaram explicitar os elementos cuja redação não teria ocorrido ao nível do pretendido e acrescentar mais elementos sobre o projeto.

Nesse novo documento é ressaltado que se tratava da proposição de um curso de pós-graduação que representaria algo novo e necessário para a região oeste do interior paulista, para a Universidade Estadual Paulista "Júlio de Mesquita Filho" e para a área de formação de professores, uma vez que:

- inúmeros profissionais da educação se viam obrigados a longas viagens à Capital devido às exigências de aprofundamento na área, o que, certamente, viria ao encontro da política de descentralização das oportunidades educacionais, criando assim um novo pólo de reflexão e ação em educação;

- existiam necessidades locais e regionais em educação que estavam a exigir tratamento específico e original, dada à viabilidade das soluções educacionais tradicionais. Daí que, então, decorria o objetivo central do Curso de Pós-Graduação em Marília, de formação do educador “[...] capaz de analisar criticamente o conhecimento pedagógico existente e propor formas orgânicas de atuação que [dessem] conta da solução de problemas específicos a nível de escolarização básica.” (UNESP.FEFCSD, 1985, p. 1013); 
- apostavam nas potencialidades do ensino como pólo integrador, como "[...] grande tema da pós-graduação em educação do Campus de Marília." (p. 1014):

- compartilhavam do desejo de buscarem, sob um novo prisma, discutir e refletir questão da natureza e da função da administração escolar " [...] no contexto de um novo tempo histórico". (p. 1013). Acreditavam que era nisto que poderia residir a originalidade e a radicalidade do projeto:

[...] refletir, pesquisar e atuar no sentido de pensar a escola como o espaço organizacional capaz de garantir a apropriação significativa do saber, do conhecimento, da cultura e da técnica ao maior número possível de indivíduos [...] privilegiar a dimensão do ensino como aspecto mais diretamente ligado à recuperação da dimensão qualitativa da escola pública estatal.

Enfim, a equipe responsável pelo projeto da Pós-Graduação em Educação em Marília afirmava estar consciente da necessidade de debates profundos e constantes com os professores, tanto para encaminhar possíveis soluções e inúmeros problemas que viessem a se interpor na implantação quanto nos momentos de avaliação e aprimoramento permanentes do curso.

Mesmo com todo o entusiasmo dos professores que estiveram à frente das primeiras iniciativas para a instalação da Pós-Graduação em Educação na Unesp de Marília, as resistências contrárias foram muitas e de diversas ordens.

Dentre essas resistências, sobretudo com relação ao projeto de implantação da Pós-Graduação em Educação da Unesp de Marília, estava a referente ao que foi denominado de "linha básica" do curso, pois se tratava de um projeto que visava a configuração de um espaço de discussões sobre as questões da educação à luz dos aspectos contextuais brasileiros, o que necessitava, inclusive, da credibilidade dos próprios professores da Unesp em geral.

Tratava-se, portanto, de busca da afirmação da Unesp de Marília, dentre os demais campi, como esse espaço de tendência crítica, a exemplo de outros cursos de Pós-Graduação, como o da UFMG e o da UFSCar, implantados ou reorganizados nos anos finais do período da ditadura militar e início do período de redemocratização política no Brasil (SANTOS, 2000, p. 50). Segundo Santos (p. 50), desde 1986 “[...] era possível perceber nas instituições que começavam a dar lugar ao pensamento pedagógico crítico, programas que tratavam de forma reflexiva das principais questões da Educação Brasileira." 
Sobre a linha teórica norteadora do primeiro projeto da pós-graduação da Unesp de Marília e em resposta à análise crítica dos relatores da CAPES sobre a proposta curricular, o Prof. Wilson de Faria, então em momento de se afastar da sua função de coordenador do Curso de Pós-Graduação da Unesp de Marília, em 1989, assim se manifestou:

a) Não privilegiamos uma determinada corrente teórica na área educacional, como, por exemplo, uma abordagem marxista, fenomenológica ou positivista da educação. Privilegiamos sim uma abordagem pluralista em que várias tendências fossem representadas no curriculum como um todo, ou mesmo, em alguns casos, no contexto de uma única disciplina [...]

b) Análise crítica da realidade educacional brasileira é vista a partir da ótica de cada disciplina e, naturalmente, de seu responsável. O bloco "A" de disciplinas tratará do tema "ensino" numa abordagem ampla, focando o campo de forças que atuam na área educacional, em seus vários componentes: políticos, filosóficos, administrativos, históricos, etc. Além de uma leitura crítica da realidade brasileira, tais disciplinas oferecem subsídios teóricos para que o aluno possa ter instrumentos conceituais pertinentes para melhor interpretar aspectos da realidade social e educacional. Os blocos "B" e "C" que podem ser fundidos, enfatizam aspectos de intervenção técnico-pedagógica na realidade escolar (Escola de $1^{\circ}$ e $2^{\circ}$ Graus e Ensino Superior). Essa abordagem técnica, no entanto, não elimina uma visão crítica da educação escolarizada brasileira. Pelo contrário, pois a intervenção técnica implica saber como é essa realidade educacional, que conteúdos são os mais viáveis para essa intervenção e que áreas educacionais podem e devem merecer tal intervenção. (UNESP.FEFCSD, 1989, p. 16-17). ${ }^{3}$

Também, é possível afirmar que, o tratamento reflexivo às questões da Educação Brasileira que então se projetava mediante a criação de uma PósGraduação em Educação em Marília, foi, certamente, uma decorrência natural da trajetória de formação e atuação nos vários âmbitos do ensino público paulista dos professores que estiveram envolvidos com as primeiras idéias e iniciativas para que essa criação ocorresse.

3 Bloco "A": Domínio específico: "Supervisão, Administração e Ensino", "História da Educação Brasileira: República" e "Educação Popular: um desafio conceitual, educacional e político"; Domínio conexo: "Educação Especial no Brasil," "Administração e Organização da Educação no Brasil". Blocos "B" e "C": Domínio específico: "Teorias de Ensino Contemporâneas" (substituindo "Planejamento de Ensino"), "Tópicos Especiais de Currículo e Programas", "Ensino e Aprendizagem Verbal Significativa", "O Lúdico e o Ensino: organização formal de elementos culturais pelo professor", "Psicologia Social do Ensino" (o título sofreu alteração), "Avaliação da Educação" (nome provisório) e "Estudos Avançados sobre o Ensino de 1" e $2^{\circ}$ Graus". (UNESP.FEFCSD, 1989, p. 14-16). 
Em coerência com a linha básica privilegiada e em atendimento às exigências feitas durante o processo de aprovação de implantação de um curso de Pós-Graduação em Educação em Marília, das duas áreas de concentração que a princípio haviam sido projetadas, o Curso de Pós-Graduação em Educação da Unesp iniciou as suas atividades em agosto de 1988, “[...] mediante um projeto básico que estabelecia a articulação das atividades de mestrado e de doutorado, ao mesmo tempo em que estabelecia também um período de maturação necessário à implantação deste segundo nível [...]" (UNESP, 1997, p. 1).

Tendo-se previsto desde o início que o projeto, desde as suas origens, estabelecia a criação do doutorado, o fato de a Pós-Graduação em educação da Unesp de Marília ter sido criado como Curso e não como Programa, se deveu, segundo o Prof. C. A. S. Jr., ao fato de que parecia algo resolvido e não se havia reflexão alguma sobre esse aspecto, visto que a Pós-Graduação em Educação, tanto na Usp quanto na Unicamp era denominada de Curso, mesmo se tendo a visão de que se tratava de Programas. Com relação à Pós-Graduação das universidades federais, o professor mencionado afirmou que acontecia exatamente o contrário, pois, apesar de ser chamada de Programa, a visão que se tinha era a de que se tratava de Curso.

Como afirmou o Prof. C. A. S. Jr. talvez teria sido em virtude da existência da diversidade de entendimento das universidades estaduais e das federais que o pessoal da CAPES que avaliou o projeto, não havia se dado conta que, mesmo chamado de Curso de Pós-Graduação, no projeto inicial da Pós-Graduação em Educação da Unesp de Marília estabelecia uma etapa de mestrado e uma etapa de doutorado.

Assim, o Curso de Pós-Graduação em Educação da Unesp de Marília iniciou as suas atividades com uma única área de concentração "Ensino na Educação Brasileira". Essa área de concentração constituiu-se com quatro (04) linhas de pesquisa, às quais se vincularam as disciplinas a serem oferecidas, aspecto inovador, segundo Santos (2000, p. 49), já que, à época, os programas de pós-graduação previam, normalmente, "[...] apenas disciplinas vinculadas diretamente à área de concentração e não às linhas de pesquisa."

Além do fato da implantação do Curso de Pós-Graduação em Educação na Unesp de Marília e, posteriormente, do Programa, ter se constituído, à época, em "frentes de lutas", teria havido uma outra, conforme o Prof. C. A. S. Jr., com a própria reitoria da Unesp, que era a de tornar o Curso de Pós-Graduação em Educação da Unesp de Marília inovador e integrador de docentes qualificados e de pesquisas em educação das várias áreas a fim, não apenas do campus de Marília como dos vários campi da Unesp. 
Nas palavras desse Professor, a Pós-Graduação em Educação da Unesp de Marília, após todas essas iniciativas, "[...] acabou tendo um efeito de matriz geradora de outros programas em áreas afins no campus de Marília e de outros programas de pós-graduação em educação [...]" (SILVA JR., 2009, p. 60), e, nesse momento, teria faltado ousadia por parte do pessoal da reitora da Unesp para articular todas essas propostas de programa na proposta do Programa de Marília.

\section{O PROGRAMA DE PÓS-GRADUAÇÃO EM EDUCAÇÃO DA UNESP DE MARÍLIA E A PÓS-GRADUAÇÃO NO BRASIL: DESAFIOS HISTÓRICOS}

Ao buscar atender às suas urgências, como mencionado, a de reunir um corpo docente para a implantação do doutorado e, consequentemente, de um Programa de Pós-Graduação stricto sensu em nível de mestrado e de doutorado, buscou o tratamento de uma questão que permeia, historicamente a área da educação, que é a de ser considerada uma área menor no âmbito das humanidades. Sendo assim, refletindo as preocupações de época manifestas, sobretudo, em eventos científicos de relevância e repercussão para a área da educação, como nas reuniões da Anped e nas reuniões dos coordenadores de Programas de Pós-Graduação em Educação, preocupações com questões da educação decorrentes dessa visão de subordinação que representantes de outras áreas nutriam sobre a educação, tratou-se, como afirmou o Prof. C. A. S. Jr. de buscar, mediante sua própria iniciativa como coordenador do Programa, o empreendimento de ações para a integração de docentes qualificados e de pesquisas das várias subáreas de humanas em um Programa de Pós-Graduação em Educação. Nesse sentido, duas frentes de ações se impuseram.

Numa primeira frente de ações, buscou-se reunir os professores dos vários cursos da unidade e outra dos outros campi da Unesp, alguns dos quais livredocentes ainda não vinculados a qualquer Programa, simplesmente porque não haviam Programas nas suas Unidades de origem. Nasciam, então, as primeiras ações para uma política de credenciamento de professores que, com o passar dos anos, foi se fortalecendo no sentido de inserirem objetos de estudo nos eixos temáticos das linhas de pesquisa, fortalecendo-as, portanto.

Foi nessa perspectiva que, então, ocorreu a reestruturação do Programa de Pós-Graduação em Educação da Unesp de Marília iniciada em 1999, tendo como orientação geral: a manutenção do caráter de amplitude, porém deli- 
mitando internamente as áreas de conhecimento e reordenando as linhas de pesquisa e disciplinas existentes; a preparação para implementação das novas diretrizes para a pós-graduação emanadas dos órgãos superiores das Universidades; a adequação às recomendações feitas pela comissão de avaliação da CAPES e às reflexões sobre a avaliação feita pelo Programa e, finalmente, retomar as intenções primeiras da proposta de criação do curso, de possuir duas áreas de concentração. Entendiam que, as atividades para a produção e disseminação do conhecimento novo, ao mesmo tempo em que contribuiriam “[...] para o entendimento de que o ensino é a razão de ser da administração e evidenciar a responsabilidade social de que se reveste o trabalho do professor e do administrador da educação", proporcionariam condições para que fossem elucidados e avaliados, criticamente, os princípios norteadores de sua prática. Nas palavras de um dos professores que estiveram à frente do projeto inicial da Pós-Graduação em Educação da Unesp de Marília “[queriam], enfim, contribuir para que se [estabelecesse] o significado da relação meios e fins na educação brasileira" (UNESP.FEFCSD, 1985, p. 13).

Buscou-se assim, manter um caráter de amplitude, que se tornou aspecto tradicional do Programa, porém sempre buscando evitar dispersão no interior de cada uma das linhas de pesquisa, idéia essa que serviu de suporte em vários momentos para as discussões e redistribuição das disciplinas no interior das linhas, de maneira a favorecer maior vinculação entre a proposta, as áreas de concentração, as linhas de pesquisa, os projetos de pesquisa e as dissertações e teses do Programa. Isso levou a um aperfeiçoamento, a cada ano, e uma maior clareza e definição dos orientadores já nos processos de seleção de candidatos para os anos seguintes, mediante análise dos projetos de pesquisa apresentados. Tratou-se, portanto, de um processo de busca pela delimitação de temáticas e de objetos de pesquisa que, aliada a um constante aprimoramento frente às normas regimentais, evidenciava contribuições para o fortalecimento das linhas de pesquisa e, consequentemente, das áreas de concentração que, uma vez articuladas à proposta teriam buscado o fortalecimento da identidade do Programa.

Numa segunda frente de ações, buscou-se contar com as colaborações de professores de outras universidades e instituições de ensino superior, mediante parcerias que se fortaleceram e fomentaram outras com as quais o Programa conta até os dias atuais.

Segundo o Prof. C. A. S. Jr., sobretudo as ações iniciais de uma política de credenciamento que marcaram o caráter de amplitude do Programa de Pós-Graduação em Educação da Unesp de Marília, conduzem à 
reflexões sobre a situação de desequilíbrio, quanto à representatividade nos órgãos colegiados nacionais, dos Programas das universidades estaduais paulistas perante os das federais, considerando-se mesmo o porte institucional dessas instituições, muito maior no caso das primeiras.

\begin{abstract}
Prof. C. A. S. Jr: Pelo próprio porte institucional das universidades estaduais paulistas, elas acabam sendo uma espécie de mundo especial num mundo que já é, em si mesmo, especial da pós-graduação em educação, porque há todo um conjunto de mal entendidos e distorções que, a rigor não tem como ser superado, por exemplo, a questão de votação por alguma coisa no fórum de coordenadores: nós perdemos sempre porque nós somos três (03), então quanto menor o Programa maior possibilidade ele tem de existir, é claro, então o que ocorre? Existem 50 ou mais programas de pós-graduação em educação no âmbito das universidades federais; fora a Uel e a Uem que são universidades estaduais de grande porte, existem mais duas ou três estaduais, a do Ceará, do Rio de Janeiro, não sei, talvez sejam essas duas mesmo, que têm programas de pós-graduação também. Então se tem um desequilíbrio na composição geral dos programas, considerando o universo dos programas, então o que acontece: as universidades estaduais não chegam a ser $10 \%$ do conjunto de universidades que mantêm programas de pós-graduação em educação, só que elas são mais de 50\% da força de trabalho (SILVA JR., 2009, p. 61-62).
\end{abstract}

Conforme afirmações do Prof. C. A. S. Jr., com as ações iniciais de credenciamento de docentes, foi possível contar com um conjunto de cerca de 60 ou 70 pesquisadores credenciados, num momento em que o Programa da Unicamp já tinha mais de 80 e o da Usp já contava com mais de 100 pesquisadores. Entretanto, mesmo com cerca de 250 pesquisadores credenciados, esses três (03) Programas valiam um (01) voto cada um em importantes processos decisórios realizados em nível dos órgãos colegiados nacionais, ficando sempre em desvantagem com relação aos Programas das universidades federais que, embora muito pequenos, como são até hoje, com oito (08), 10, no máximo 15 pesquisadores, são em maior quantidade, somando, portanto, uma maior quantidade de votos em situações para se decidir sobre questões educacionais polêmicas.

Prof. C. A. S. Jr.: Então, o que acontecia: na hora das decisões sobre questões polêmicas, nós [os Programas das universidades 
paulistas e seus representantes] perdíamos sempre, como devemos perder até hoje. Agora não acompanho mais esse movimento, mas se você entrevistar o coordenador atual da Usp, que é o Romualdo, e a coordenadora atual da Unicamp, que eu não sei quem é, provavelmente eles vão dizer, claro que as coisas mudaram um pouquinho, mas vão dizer que essa situação estruturalmente não se alterou, quer dizer, a representação da produção acaba sendo deformada pelo critério de representação política, que é simplório, eu ia dizer singelo, mas é na verdade simplório, quer dizer, seria preciso pensar em uma outra forma de representação nos órgãos colegiados nacionais, para que o conjunto da produção científica se evidenciasse tal como ela de fato se manifesta (SILVA JR., 2009, p. 61-62).

Como se observa, a busca pelo não desequilíbrio quanto à representatividade política dos Programas de Pós-Graduação das universidades estaduais com relação aos das federais foi outra frente de luta do Programa de Pós-Graduação da Unesp de Marília, no período em que foi coordenado pelo Prof. C. A. S. Jr.

Outra questão sobre a qual a trajetória do Programa de Pós-Graduação em Educação da Unesp de Marília oferece subsídios para se empreender novos debates, também diz respeito ao porte institucional das universidades que possuem Programas de Pós-Graduação em Educação. Trata-se da questão quanto à exigência de super especialização dos Programas de Pós-Graduação.

Como afirma o Prof. C. A. S. Jr., tanto a USP quanto a Unicamp e, provavelmente a Unesp, são vistas, até hoje, como instituições demasiadamente genéricas no que se refere às suas propostas de Programa. Daí, então que:

[...] um dos cuidados maiores que os coordenadores [do Programa de Marília] têm de sempre procurar mostrar que tal dissertação tem a ver com tal projeto, para o pessoal ver que tem a ver com tal orientador etc. Porque essa é uma política que eles já sabem que, fatalmente ocorrerá, porque nós não temos um objeto tão circunscrito, tão específico, quanto em outros programas (SILVA JR., 2009, p. 63).

Entretanto, é possível afirmarmos que, um estudo aprofundado sobre os Programas das universidades federais, apesar de serem vistos como especializados, alguns até como super especializados, pode revelar que são, na verdade, Programas "[...] tão genéricos quanto os nossos com a agravante que tem menos gente para cuidar dessa generacidade [...] (p. 63).

Caso persistam essas concepções que atribuem à especialização ou não de um Programa ao seu porte institucional ou à quantidade de docentes que agre- 
ga, sob a alegação de que se deve ser pequeno para o aprofundamento em determinada temática, concordamos com o Prof. C. S. Jr. quando ele afirma que:

[...] a USP, a Unesp e a Unicamp nunca serão reconhecidas como os melhores Programas do Brasil. Pode ser até que não tenham mesmo condições de merecer, não sei, mas [...] de certa maneira são condenadas a serem o segundo, o terceiro bons, mas nunca excelentes (SILVA JR., 2009, p. 63-64).

\section{ALGUMAS CONSIDERAÇÕES FINAIS}

Como ressaltado por Gatti (2001, p. 111) "o futuro da pós-graduação está ancorado em sua história específica em nosso país e em como se apresenta no momento." Nesse sentido, a vocação e identidade de cada um dos cursos e programas da pós-graduação, suas diversidades nas várias regiões e até mesmo dentro de uma região, a avaliação da trajetória pregressa e da evolução de cada um e seu contexto institucional, bem como as suas perspectivas de trajetória futura, concorrem para essa história e para a redefinição e aperfeiçoamento dos aspectos da política de Pós-Graduação no Brasil.

Sendo assim, nos propomos a investigar aspectos da trajetória da Pós-Graduação em Educação da Unesp de Marília, durante seus 20 primeiros anos de existência, entre 1988 e 2008, pois, como pudemos constatar, além de ter sido pioneira sob vários aspectos que incidiram na sua própria dinâmica de instalação e de funcionamento, propôs-se a pensar nas suas próprias urgências associando-as a importantes questões acerca da educação e, particularmente, acerca da Pós-Graduação no Brasil, em favor do quê abriu frentes de luta que acabou por conferir-lhe certa originalidade.

Assim, neste artigo, abordarmos questões que têm se colocado como desafios e que, historicamente, permanecem em aberto, referentes ao desequilíbrio quanto à representatividade política dos Programas das universidades estaduais com relação aos das estaduais e à exigência de super especialização dos Programas quanto às suas propostas de investigação.

Concluímos, ao final, que, embora já se tenha avançado nas discussões dessas questões, decorrentes do próprio porte institucional das universidades em que se encontram os Programas e da quantidade de pesquisadores que agregam, ainda interferem na avaliação da produção dos Programas, tornando-se, portanto, merecedores de serem consideramos numa agenda de discussões sobre a Pós-Graduação no Brasil. 


\section{REFERÊNCIAS}

CORDOVA, Rogério de Andrade; GUSSO, Divonzir Arthur; LUNA, Sérgio Vasconcelos. A pós-graduação na América Latina: o caso brasileiro.

Brasília, DF: Unesco: Cresalc: MEC, SESu: CAPES; Santa Maria: Imprensa Universitária da Universidade de Santa Maria, 1986.

GATTI, Bernardete Angelina. Reflexão sobre os desafios da pós-graduação: novas perspectivas sociais, conhecimento e poder. Revista Brasileira de Educação, Rio de Janeiro, n.18, p. 108-116, set./dez. 2001.

MAGNANI, Maria do Rosário Mortatti. Em sobressaltos: formação de professora. Campinas: Ed. Unicamp, 1993.

. Os sentidos da alfabetização: a "questão" e a constituição de um objeto de estudo (São Paulo - 1876/1994). 1997. Tese (Doutorado) - Faculdade de Ciências e Tecnologia, Universidade Estadual Paulista, Presidente Prudente, 1997.

MORTATTI, Maria do Rosário Longo. Os sentidos da alfabetização: São Paulo/ 1876-1994. São Paulo: Ed. Unesp, 2000.

SANTOS, Cássio Miranda dos. Tradições e contradições da pósgraduação no Brasil. 2000. Tese (Doutorado em Educação) - Faculdade de Filosofia e Ciências, Universidade Estadual Paulista, Marília, 2000.

SILVA JR., Celestino Alves da. Entrevista concedida ao pesquisador em 20/03/2009. Marília, 2009.

UNESP - UNIVERSIDADE ESTADUAL PAULISTA. FFC - Faculdade de Filosofia e Ciências. Curso de Pós-Graduação em Educação. Autuação dos documentos referentes à composição do Conselho de Curso de PósGraduação em Educação - Área de Ensino na Educação Brasileira.

Marília, 1989. 220f.

UNESP - UNIVERSIDADE ESTADUAL PAULISTA. FFC - Faculdade de Filosofia e Ciências. Curso de Pós-Graduação em Educação. Relatório Capes 1996: Informações complementares. Marília, 1997.

UNESP - UNIVERSIDADE ESTADUAL PAULISTA. FEFCSD - Faculdade de Educação, Filosofia, Ciências Sociais e da Documentação. Curso de 
Pós-Graduação em Educação. Criação do curso de pós-graduação em educação, a nível de Mestrado, com as áreas de Concentração "Ensino na Educação Brasileira" e "Administração da Educação Brasileira”. Marília, 1985. 4v. Processo n. 470/85, de 24/01/1985. 